\title{
Wnt antagonism initiates cardiogenesis in Xenopus laevis
}

\author{
Valerie A. Schneider and Mark Mercola ${ }^{1}$ \\ Department of Cell Biology, Harvard Medical School, Boston, Massachusetts 02115, USA
}

\begin{abstract}
Heart induction in Xenopus occurs in paired regions of the dorsoanterior mesoderm in response to signals from the Spemann organizer and underlying dorsoanterior endoderm. These tissues together are sufficient to induce heart formation in noncardiogenic ventral marginal zone mesoderm. Similarly, in avians the underlying definitive endoderm induces cardiogenesis in precardiac mesoderm. Heart-inducing factors in amphibians are not known, and although certain BMPs and FGFs can mimic aspects of cardiogenesis in avians, neither can induce the full range of activities elicited by the inducing tissues. Here we report that the Wnt antagonists Dkk-1 and Crescent can induce heart formation in explants of ventral marginal zone mesoderm. Other Wnt antagonists, including the frizzled domain-containing proteins Frzb and Szl, lacked this activity. Unlike Wnt antagonism, inhibition of BMP signaling did not promote cardiogenesis. Ectopic expression of GSK3 $\beta$, which inhibits $\beta$-catenin-mediated Wnt signaling, also induced cardiogenesis in ventral mesoderm. Analysis of Wnt proteins expressed during gastrulation revealed that Wnt3A and Wnt8, but not Wnt5A or Wnt11, inhibited endogenous heart induction. These results indicate that diffusion of Dkk-1 and Crescent from the organizer initiate cardiogenesis in adjacent mesoderm by establishing a zone of low Wnt3A and Wnt8 activity.
\end{abstract}

[Key words: Dkk1; Wnt; heart induction; cardiogenesis; dorsal mesoderm]

Received September 28, 2000; revised version accepted November 16, 2000.

The heart in all vertebrates arises from paired regions of cardiogenic mesoderm located in dorsoanterior mesoderm. In Xenopus, this tissue lies within a portion of the equatorial region of the embryo (the marginal zone) located between $30^{\circ}$ and $45^{\circ}$ to either side of the dorsal midline flanking the Spemann organizer. Heart induction is largely complete by early gastrulation (Sater and Jacobson 1989, 1990; Nascone and Mercola 1995).

The Spemann organizer and the dorsoanterior endoderm that underlies the precardiac mesoderm are both necessary for induction and together are sufficient to induce beating heart tissue in noncardiogenic ventral marginal zone mesoderm (Nascone and Mercola 1995). Heart induction in Xenopus resembles the same process in avians, in which the cardiogenic mesoderm, located on either side of the anterior primitive streak, is induced by interactions with underlying definitive endoderm (Antin et al. 1994; Sugi and Lough 1994; Schultheiss et al. 1995).

Although several proteins have been implicated in the induction of cardiogenic mesoderm, their specific roles in this process are not entirely clear and additional factors are likely to be involved. Members of the bone morphogenetic protein (BMP) family are expressed adjacent

${ }^{1}$ Corresponding author.

E-MAIL mmercola@hms.harvard.edu; FAX (617) 975-0538.

Article and publication are at www.genesdev.org/cgi/doi/10.1101/ gad.855601. to the heart-forming region in avians, and ectopic expression of the BMP antagonist noggin in chick precardiac mesoderm inhibits cardiogenesis (Schultheiss et al. 1997; Schlange et al. 2000). Conversely, application of BMP2 or BMP4 to chick anterior mesoderm located medial to the heart forming region induces ectopic cardiogenesis (Schultheiss et al. 1997; Andree et al. 1998). However, these BMPs cannot mimic the ability of endoderm to induce cardiogenesis in more posterior mesoderm, indicating the involvement of additional factors (Schultheiss et al. 1997). Two lines of experiments using Xenopus embryos also indicate that factors other than BMPs are required for initiation of cardiogenesis. First, inhibition of endogenous BMP signaling with a dominant negative type I receptor blocked maintenance but not initial expression of Nkx2.5, a homolog of the Drosophila tinman gene and an early marker of heart field specification (Shi et al. 2000). Second, mRNAs encoding BMP isoforms are not expressed by either of the tissues known to have heart-inducing activity, the dorsoanterior endoderm or the Spemann organizer (Isaacs et al. 1992, 1995; Tannahill et al. 1992; Suzuki et al. 1993; Song and Slack 1994; Clement et al. 1995; Yamagishi et al. 1995; Jones et al. 1996). In avians, fibroblast growth factor (FGF) family members have been proposed to work in conjunction with BMPs, but in Xenopus, their mRNAs are also not expressed in heart-inducing tissues, again 
suggesting the participation of additional factors in cardiogenesis.

Studies have also indicated that an activin-like activity might be involved in heart induction. Treatment of avian posterior epiblast tissue with activin-induced cardiac myogenesis (stage XI-XIV, staging according to Eyal-Giladi and Kochav 1976; Yatskievych et al. 1997; Ladd et al. 1998). However, the inability of this protein to induce heart muscle cells in streak stage mesodermal explants (the period when heart induction normally occurs) indicate that the role of activin in this process might be indirect, possibly by promoting the formation of precardiac mesoderm competent to respond to heartinducing signals. Similarly, induction of cardiogenesis in Xenopus animal cap tissue by ectopic activin expression correlates with formation of both dorsal mesoderm and endoderm (Logan and Mohun 1993; Henry et al. 1996), raising the possibility that heart induction occurred because of interactions between these tissues.

Finally, several experiments have implicated Cerberus, a member of the DAN family of secreted proteins that inhibit signaling by BMP, Wnt, and Nodal-related proteins, in cardiogenesis (Bouwmeester et al. 1996; Hsu et al. 1998; Pearce et al. 1999; Piccolo et al. 1999; Belo et al. 2000). Cerberus homologs are expressed in heart-inducing tissues in mouse (Belo et al. 1997; Biben et al. 1998; Shawlot et al. 1998), chick (Esteban et al. 1999; Yokouchi et al. 1999; Zhu et al. 1999), and Xenopus (Bouwmeester et al. 1996; Schneider and Mercola 1999) and can induce expression of Nkx2.5 in Xenopus animal cap tissue (Bouwmeester et al. 1996; Belo et al. 1997; Biben et al. 1998). However, as Cerberus does not induce expression of markers of terminal cardiac differentiation (Biben et al. 1998; V. Schneider and M. Mercola, unpubl.) and hearts develop in mice lacking the murine homolog Cerberus-like (Simpson et al. 1999; Belo et al. 2000), the cardiogenic function of Cerberus proteins, if any, remains elusive. Taken together, these data indicate that additional factors are necessary to initiate cardiogenesis in both vertebrate embryos.

The requirement for the Spemann organizer in heart induction led us to ask whether organizer-derived factors have heart-inducing activity. Secreted factors produced by the Spemann organizer in Xenopus have been studied intensely and shown to be important for pattern formation both before and during gastrulation (for review, see Harland and Gerhart 1997). Dorsalizing activity of the organizer is mediated by Nodal-like signaling as well as by specific antagonists of BMP (Chordin and Noggin) and Wnt signaling (Frzb, Dkk-1, and Crescent; Sasai et al. 1994; Jones et al. 1995; Zimmerman et al. 1996; Leyns et al. 1997; Wang et al. 1997a; Glinka et al. 1998; Pera and De Robertis 2000). Embryological studies of these proteins have revealed potent dorsoanteriorizing effects on the mesoderm and ectoderm. Importantly, antagonism of Wnt and BMP activities are not entirely redundant but appear complementary. For instance, Glinka et al. (1997) provided evidence that inhibition of BMP signaling alone results in tail organizing activity, whereas inhibition of both BMP and Wnt pathways promotes the generation of head structures anterior to the midhindbrain. Thus, both the expression of BMPs and Wnts and their inhibition are important aspects of the generation of early embryonic pattern. Moreover, at least one Wnt (Wnt11) has been implicated in early chick cardiogenesis (Eisenberg and Eisenberg 1999).

Here we show that expression of the Wnt antagonists Dkk-1 and Crescent is sufficient to induce heart formation in noncardiogenic ventral marginal zone mesoderm. This activity is not shared by other antagonists of Wnt signaling, nor the BMP antagonists Noggin and Chordin, indicating that inhibition of specific Wnts may be required. Analysis of Wnt proteins expressed at the onset of gastrulation indicated that only Wnt3A and Wnt8, but not Wnt5A and Wnt11, were capable of inhibiting endogenous heart induction. The data indicate a model in which diffusion of Dkk-1 and Crescent from the Spemann organizer region initiates cardiogenesis in the immediately adjacent mesoderm by creating a zone of reduced Wnt3A and Wnt8 activity.

\section{Results}

Dkk-1 and Crescent, but not Frzb, can induce heart-specific gene expression in noncardiogenic mesoderm

Our previous studies showed that beating hearts having lumens lined by endothelial cells can be induced in explants of noncardiogenic ventral marginal zone (VMZ) mesoderm by exposure to both the Spemann organizer and dorsoanterior endoderm (Nascone and Mercola 1995). In a modification of this assay (Fig. 1A), we targeted mRNAs encoding Wnt and BMP antagonists to VMZ tissue by microinjection into the equatorial region of both ventral blastomeres of four-cell stage embryos. VMZ explants were isolated at stage 10, cultured, and assayed at stage 30 by RT-PCR for cardiac-specific gene expression.

$d k k-1$ encodes a secreted protein capable of antagonizing Wnt signaling that is normally expressed in the Spemann organizer region of stage 10 embryos /Glinka et al. 1998). We find that ectopic expression of $d k k-1$ in VMZ explants at doses of $450 \mathrm{pg}$ or greater induces abundant expression of $N k x 2.5$ and Tbx5, two homeobox genes that mark the early heart field (Fig. 1B; Tonissen et al. 1994; Newman and Krieg 1998; Horb and Thomsen 1999). In addition, the same doses of $d k k-1$ also promote the strong expression of TnIc and $M H C \alpha$, which encode cardiomyocyte-specific contractile proteins (Fig. 1B; Logan and Mohun 1993; Drysdale et al. 1994). In situ hybridization demonstrated that TnIc transcripts were highly localized in the VMZ explants (Fig. 1C).

crescent encodes a Wnt antagonist containing a frizzled-like cysteine-rich domain that is also expressed in the Spemann organizer region in a pattern overlapping that of $d k k-1$ (Pera and De Robertis 2000). We find that crescent, like $d k k-1$, is a potent inducer of both early and late heart-specific gene expression in VMZ tissue (Fig. 1B). Robust expression of cardiac-specific genes was induced following injection of 900 pg of chick crescent 
Figure 1. $d k k-1$ and crescent, but not frzb, induce cardiac specific gene expression in noncardiogenic tissue. $(A)$ mRNAs encoding various Wnt and BMP antagonists were injected equatorially into ventral blastomeres at the four-cell stage. Ventral marginal zone (VMZ) tissue was then explanted at stage 10 and cultured until analyzed by RT-PCR for gene expression at stage 30 (see Materials and Methods). (B) Injection of $d k k-1$ or crescent induced both markers of cardiac mesoderm (Tbx5 and Nkx2.5) and heart muscle-specific genes (cardiac isoform of troponin-I, TnIc, and myosin heavy chain- $\alpha, M H C \alpha)$ in VMZ tissue. frzb, in contrast, induced muscle actin (m. actin), which is primarily a skeletal muscle marker, but not cardiac specific gene expression. Induced genes were expressed at levels comparable to endogenous expression in control dorsal marginal zone (DMZ) explants. (C-E) TnIc transcripts induced by injection of $1.5 \mathrm{ng}$ of $d k k-1$ or crescent mRNAs were highly localized, similar to endogenous expression (cf. with control DMZ shown in Figs. $3 C^{\prime}$ and $\left.5 \mathrm{G}\right)$, whereas injection of frzb mRNA does not induce TnIc. $(F, G) d k k-1$, crescent, and frzb block Wnt8 induction of Siamois in animal cap tissue. Wnt8 and Wnt antagonist mRNAs were injected into the animal region of two-cell-stage embryos and caps were isolated at stage 9, cultured, and processed for RT-PCR at stage $10.5(F)$. Antagonism of Wnt8 signaling indicates that functional protein is translated from the injected mRNAs in each case $(G)$. EF1 $\alpha$ expression is shown as a control for the RT reaction in all cases.
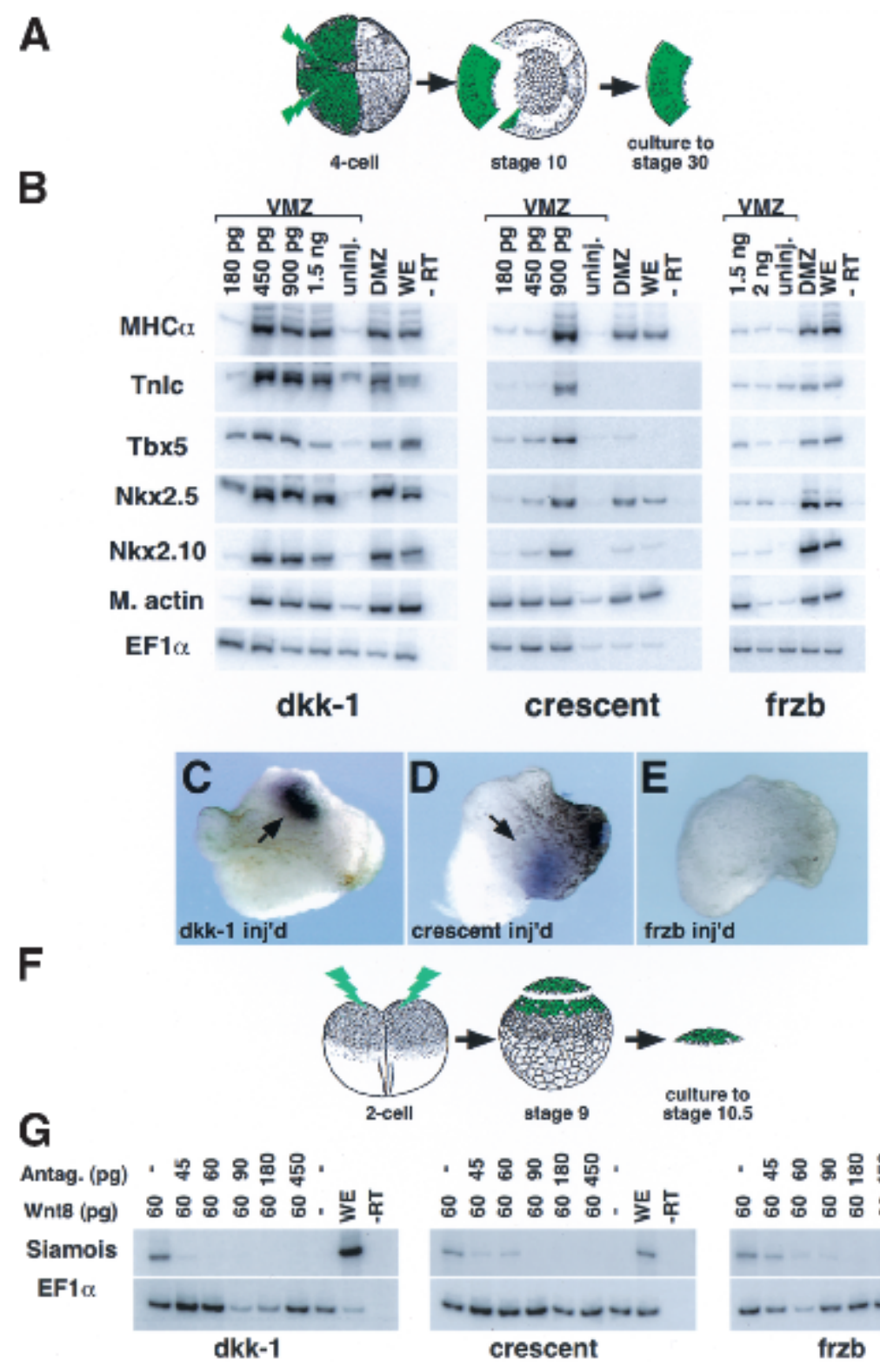

B

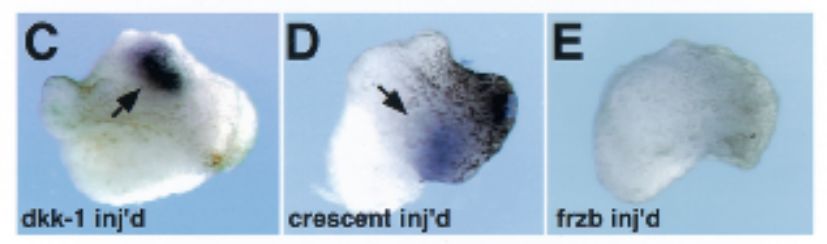

G

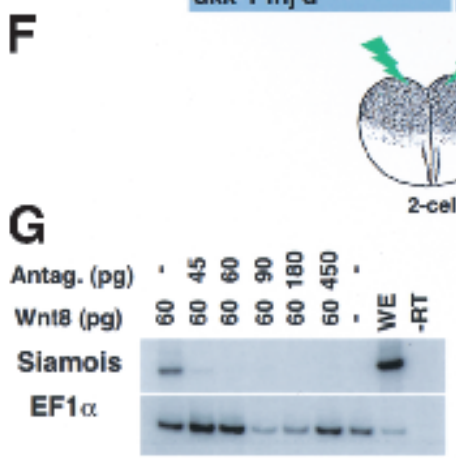

dkk-1
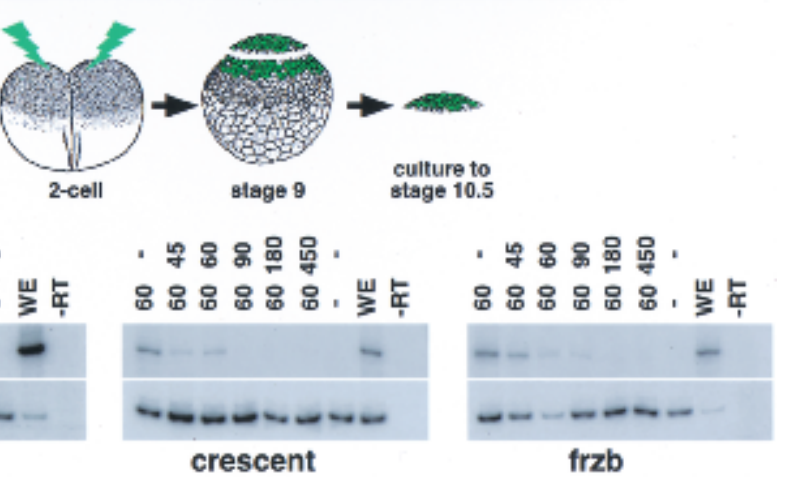

mRNA, slightly more than required with $d k k-1$. However, doses of crescent as low as $180 \mathrm{pg}$ induced expression of muscle actin, which primarily marks skeletal muscle (but is also expressed in cardiac muscle). As seen with $d k k-1$, TnIc expression induced by crescent was highly localized (Fig. 1D).

The reason for the difference in doses of $d k k-1$ and crescent mRNA required to induce muscle actin and the cardiac-specific markers was explored further by evaluating their relative ability to block Siamois induction by Wnt8 (Fig. 1F,G). Injection of $d k k-1$ mRNA yielded more potent Wnt8 antagonism than did crescent mRNA (Fig. 1G), indicating that differential antagonism of Wnt8 (or other Wnt proteins) might underlie the different activities of these two proteins. The difference in the activities of these proteins, however, could also reflect variations in the translational efficiency of their mRNAs. Nonethe- less, our data show that Dkk-1 and Crescent are both potent inducers of cardiac-specific gene expression in the VMZ.

Dkk-1 and Crescent also induced Nkx2.10, which encodes a transcription factor with homology to Nkx2.5 (Fig. 1B). Whereas transcripts for Nkx2.5 are present in both cardiac mesoderm and the underlying pharyngeal endoderm of stage 30 embryos, Nkx2.10 mRNA marks only the endodermal portion of the $N k \times 2.5$ domain at this stage (Newman and Krieg 1998; Newman et al. 2000). The observed induction of Nkx2.10 therefore indicates that both Dkk-1 and Crescent induced pharyngeal endoderm along with cardiac mesoderm in VMZ tissue. This could occur if Dkk-1 and Crescent dorsoanteriorized the deep endoderm contained in our VMZ explants that would normally contribute to posterior regions of the gut. 
Of the three Wnt antagonists known to be expressed in the Spemann organizer, only Frzb was incapable of inducing expression of genes encoding heart muscle-specific proteins in VMZ tissue (Fig. 1B,E). Despite this, microinjection of frzb mRNA efficiently induced muscle actin in VMZ tissue (Fig. 1B), antagonized Wnt8 induction of Siamois in animal caps (Fig. 1G), and produced shortened body axes when injected ventrally into embryos at the four-cell stage (data not shown), demonstrating that a lack of protein production was not likely to be responsible for this result. frzb weakly induced expression of Nkx2.5 and Tbx5 detectable by RT-PCR (Fig. 1B) but not by in situ hybridization (Fig. 1E). Tbx5, however, is also expressed in the eye at this stage (Horb and Thomsen 1999), and we observed induction of the pharyngeal endoderm marker Nkx2.10, which overlaps Nkx2.5 expression (Fig. 1B). Thus, we cannot distinguish whether ectopic Frzb in VMZ explants weakly induced early but not late stages of cardiogenesis and/or pharyngeal endoderm or, instead, activated expression of the NK2 family of genes in the absence of either heart or pharyngeal induction. The lack of heart-marker induction by Frzb may reflect a difference in the affinities of Wnt antagonists for various Wnt family members and raises the possibility, addressed below, that specific Wnts negatively regulate heart induction.

Expression of dkk-1 and crescent in VMZ explants results in the formation of beating hearts

To determine whether $d k k-1$ and crescent could promote later stages of cardiogenesis, we cultured VMZ explants injected with these mRNAs to stage 41, when beating hearts were apparent in control embryos. Remarkably, as heart induction is known to require both endodermal and organizer derived signals, we found that the injection of a single mRNA was sufficient to promote terminal cardiac differentiation. Rhythmic beating was observed on average in $73.2 \%$ of explants $(n=44)$ injected with $d k k-1$ and in $23.2 \%(n=90)$ with crescent (Fig. 2A). Uninjected VMZ control explants, in contrast, were never observed to beat $(n=66)$. frzb, which did not induce heart-specific gene expression in VMZ explants, was also unable to induce beating $(n=35)$. Strikingly, the dkk-1- and crescent-injected VMZ explants retained their ventral appearance, except for features of cardiogenesis. Explants generally formed round vesicles encapsulating beating heart tissue, with few other identifiable structures (Fig. 2). Superficially, this appearance resembled uninjected control explants and differed greatly from either VMZ explants injected with either noggin or chordin or DMZ explants, all of which developed an elongated anteroposterior body axis (Fig. 2, cf. E,H to characteristic dorsal appearance of a DMZ explant, panel B). Expression of $d k k-1$ or crescent mRNAs was noted, however, to cause an increase in melanocyte formation and to induce cement glands in these VMZ explants (90.7\% and $61.2 \%$, respectively).

Histological sections through representative explants are shown in Figure 2. Immunohistochemical staining

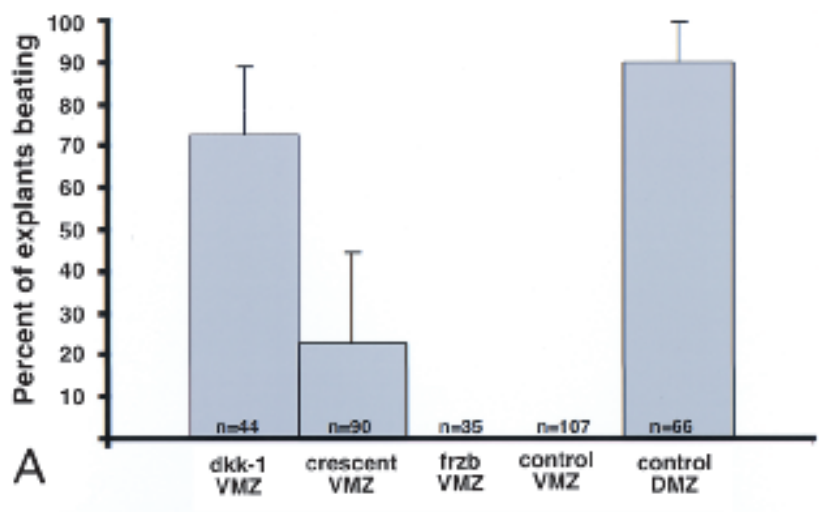

control DMZ
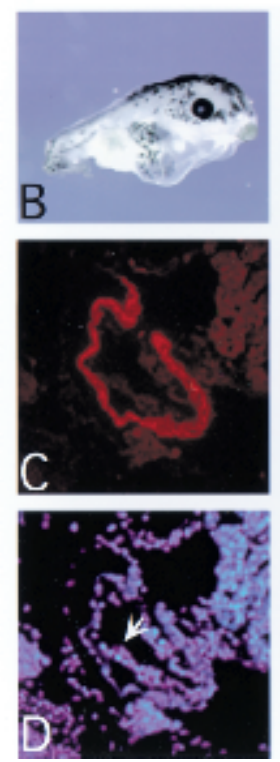

dkk-1 VMZ
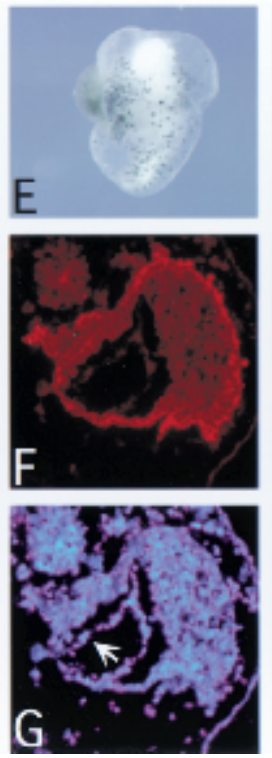

crescent VMZ
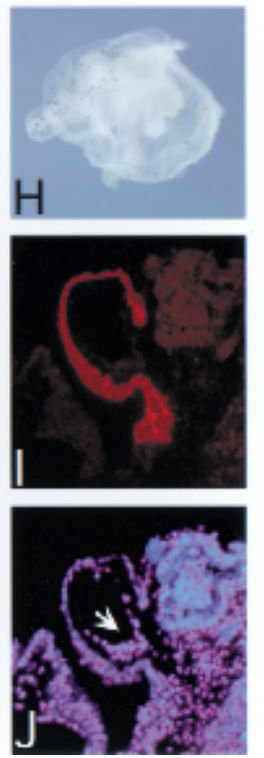

Figure 2. Injection of the Wnt antagonists $d k k-1$ and crescent resulted in the formation of beating hearts in VMZ tissue. Embryos were injected ventrally with $900 \mathrm{pg} d k \mathrm{k}-1,1.5 \mathrm{ng}$ crescent, or $1.5 \mathrm{ng}$ frzb mRNA at the four-cell stage, and VMZ explants isolated and cultured as above. $(A)$ The explants were scored for rhythmic beating when sibling controls reached stage 41. Uninjected VMZ and DMZ explants were analyzed as negative and positive controls, respectively. $(B-D)$ Control DMZ explants formed an embryoid-like structure having a well-developed anteroposterior body axis $(B)$. The heart tube contained a myocardial layer that stained with CT-3, which recognizes the cardiac isoform of troponin- $\mathrm{T}(C)$, lined by a thin layer of CT-3 negative endothelial cells visualized with DAPI (arrow in $D$ ). $(E-G) d k k-1$ injected VMZ explants formed simple structures resembling a small epithelial sac encapsulating a CT-3 positive myocardial tube $(F)$ also lined by endothelial cells $(G)$. $(H-J)$ crescent-injected VMZs formed similar structures. Pigmented melanocytes were seen scattered on the surface of the $d k k-1$ - and crescentinjected VMZ explants, and cement gland tissue was often observed (cluster of pigmented cells on surface of tissue in $E$ ). Line represents $25 \mu \mathrm{m}$.

with the polyclonal antibody CT-3, which recognizes the cardiac-specific isoform of troponin- $T$, revealed that both $d k k-1$ (Fig. 2F,G) and crescent (Fig. 2I,J) induced myocardial tubes. In all cases, the lumens of the myo- 
cardial tubes were lined by a thin layer of endothelial cells that do not stain with CT-3 (arrows in Fig. 2D,G,J). We conclude that both $d k k-1$ and crescent are sufficient to induce terminal cardiogenesis and that the ectopic hearts exhibit the morphology and gene expression characteristic of hearts that develop in intact embryos or in control DMZ explants that contain normal cardiac tissue (Fig. 2C,D).

\section{The BMP antagonists Noggin and Chordin do not} induce cardiac-specific gene expression in VMZ explants

Induction of cardiogenesis by Dkk-1 and Crescent led us to ask whether such activity is shared by the BMP antagonists Noggin and Chordin, which also dorsalize mesoderm, or whether it is a specific property of particular Wnt antagonists. Noggin and chordin are of interest because, like $d k k-1$, crescent, and frzb, they are normally expressed in the Spemann organizer. Injection of all doses of noggin mRNA tested resulted in extensive elongation of VMZ explants and doses $>50$ pg caused such extreme morphogenetic movements that explants were unable to survive until stages at which heart development could be analyzed. Doses of noggin as low as 5 pg, however, were potent inducers of dorsal mesoderm in VMZ explants, as seen by the induction of muscle actin (data not shown). None of the doses of noggin injected, ranging from 5 to $50 \mathrm{pg}$, were able to induce expression of either early or late heart markers, as compared with uninjected VMZ explants (Fig. 3A,E,E'; data not shown).

Injection of chordin mRNA caused VMZ explants to elongate and form embryoids having anteriorly truncated body axes (Fig. F, F'; data not shown), and RT-PCR analysis confirmed the induction of muscle actin (Fig. 3A). In contrast to noggin, chordin was also observed to induce low-level expression of $N k x 2.5$ and Tbx5 (Fig. 3A). As with frzb, Nkx2.5 expression after chordin injection was not detectable by in situ hybridization (Fig. 3F),
A

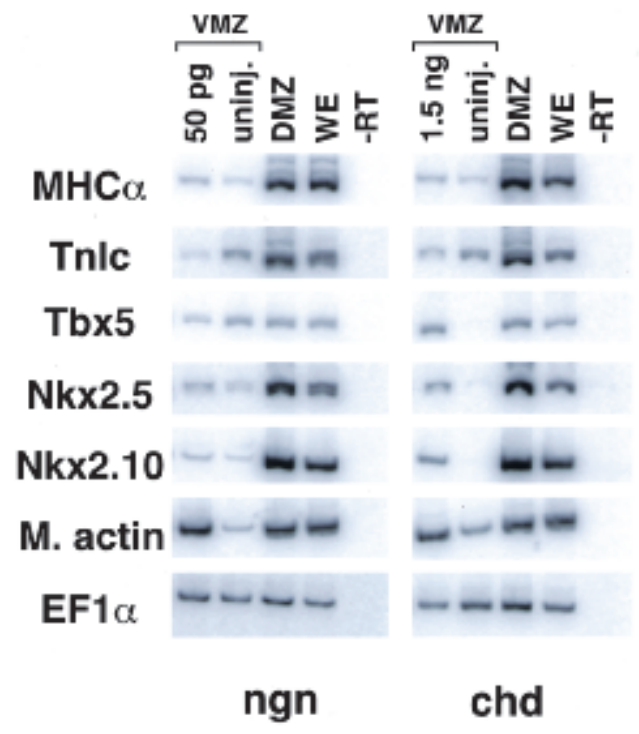

B

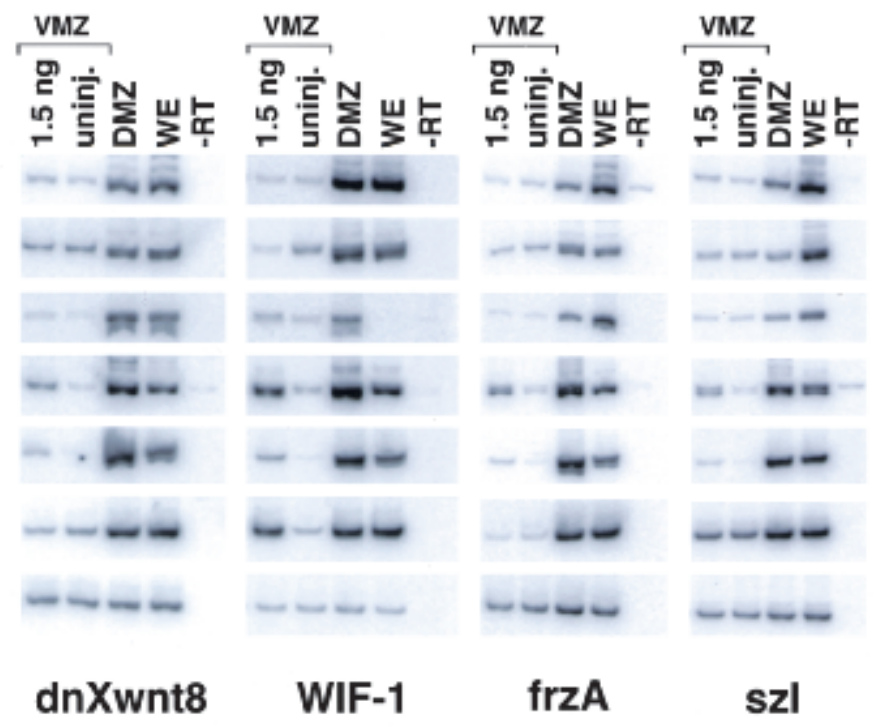

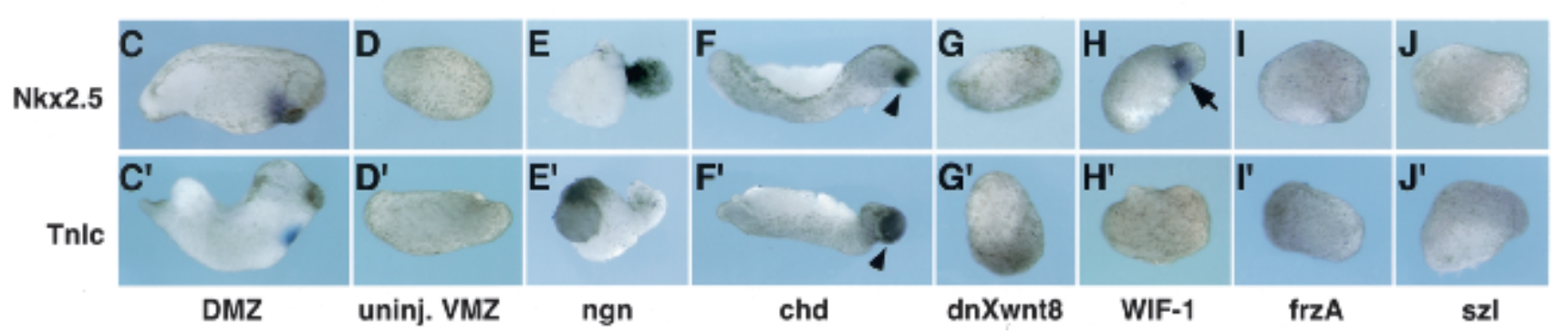

Figure 3. Induction of cardiogenesis in the VMZ assay is specific to certain Wnt antagonists. $(A)$ The BMP antagonists Noggin and Chordin did not induce specific markers of cardiogenesis (TnIc or $M H C \alpha$ ) despite induction of $m$. actin and elongation of the explants (not shown). Noggin did not induce Tbx5, Nkx2.5, or Nkx2.10, whereas chordin weakly induced these genes. Note that Tbx5 and $N k \times 2.5$ are expressed in tissues other than cardiac mesoderm and that induction of these genes (in the absence of other markers) does not necessarily indicate heart field specification (see text). (B) Wnt antagonists not normally present in gastrula-stage embryos induced weak expression of $T b x 5, N k x 2.5$, and $N k x 2.10$ but did not induce the more specific cardiac markers TnIc or MHC . In situ hybridization for expression of $N k x 2.5(C-J)$ and TnIc $\left(C^{\prime}-J^{\prime}\right)$ indicated that only WIF-1 induced detectable levels of $N k x 2.5$ expression (arrow in $H_{;} 4$ of 24 explants showed expression) and that none of these mRNAs induced TnIc. Arrowheads in $F$ and $F^{\prime}$ show pigmented cement glands that formed in explants injected with chordin mRNA. 
indicating only weak induction. Moreover, no dose tested (ranging from $180 \mathrm{pg}$ to $1.5 \mathrm{ng}$ ) could induce contractile protein mRNAs (Fig. 3A, $\mathrm{F}^{\prime}$; data not shown). The induction of the pharyngeal marker $N k x 2.10$ indicates that Chordin, well known to dorsalize ectoderm (Lamb et al. 1993), also dorsoanteriorized the endoderm present in the VMZ explants. Thus, we cannot distinguish whether Chordin, like Frzb, weakly induced early stages of cardiogenesis or activated NK2 family members in the absence of heart (or pharyngeal endoderm) induction. Despite the uncertain role of Chordin, it is clear that the induction of heart-specific mRNAs in VMZ explants is a specific property of Wnt antagonism rather than a general feature of dorsalization as mediated by BMP antagonism.

Wnt antagonists other than Dkk-1 and Crescent are unable to induce heart-specific mRNA expression in VMZ explants

To characterize the range of Wnt antagonists capable of heart induction, we examined representatives of three different classes of inhibitors: dominant negative Xenopus Wnt8 (Hoppler et al. 1996), WIF-1 (a WIF domain antagonist; Hsieh et al. 1999), and FrzA and Szl (frizzled domain antagonists; Salic et al. 1997; Xu et al. 1998). Injection of as much as $1.5 \mathrm{ng}$ of $d n X w n t 8$, which is known to inhibit Wnt1, Wnt3A, and Wnt8 (Hoppler et al. 1996), was unable to induce expression of muscle actin above levels found in control VMZ explants (Fig. 3B). In addition, only weak induction of $N k x 2.5$ and 2.10 was observed in $d n X w n t 8$-injected VMZ explants. Notably, $d n X w n t 8$ did not induce expression of the heart-specific mRNAs TnIc and MHC $\alpha$ in our experiments (Fig. 3B). The inability to induce heart-specific mRNAs was apparently not due to lack of protein production, as doses of $d n X w n t 8$ as low as 45 pg were effective at inhibiting Siamois induction in animal caps by Xwnt8 (data not shown). Similarly, WIF-1, frzA, and szl only weakly induced $X N k \times 2.5$ and 2.10 at the highest doses tested, and none induced the heart-specific contractile protein genes TnIc and $M H C \alpha$ (Fig. 3B). Of these Wnt antagonists, only WIF-1 induced expression of Nkx2.5 at levels detectable by in situ hybridization (Fig. 3G-J), and none induced detectable levels of TnIc transcripts (Fig. 3G'-J'). Sibling embryos injected with each of these mRNAs, but not dissected for VMZ explants, developed malformations characteristic of each inhibitor, indicating that the injected mRNAs yielded functional protein $(\mathrm{Wu}$ et al. 1995; Salic et al. 1997; Hsieh et al. 1999; data not shown). Thus, of the Wnt antagonists examined, only Dkk-1 and Crescent induced ectopic cardiogenesis in VMZ tissue. Previous studies have demonstrated that the various antagonists have differing abilities to block signaling from different Wnt proteins (Wang et al. 1997b; Xu et al. 1998; Dennis et al. 1999; Krupnik et al. 1999). We conclude that Dkk-1 and Crescent, which are present in the gastrula stage organizer region, induce cardiogenesis in VMZ tissue by the selective inhibition of one or more endogenous Wnt proteins.
GSK3 $\beta$, an inhibitor of $\beta$-catenin-mediated Wnt signaling, induces expression of heart-specific genes in VMZ explants

Wnt signaling is transduced by at least two different pathways, one that depends on transcription mediated by $\beta$-catenin and a second that involves the stimulation of protein kinase C (for review, see Moon et al. 1997; Sheldahl et al. 1999; Kuhl et al. 2000). To determine if $\beta$-catenin signaling must be inhibited for cardiogenesis to proceed, we tested whether the serine/threonine kinase GSK3 $\beta$ would induce heart-specific gene expression in VMZ explants. Phosphorylation by GSK3 $\beta$ targets $\beta$-catenin for ubiquitination and ultimate degradation (Aberle et al. 1997). As before, mRNA encoding GSK3 $\beta$ was injected ventrally at the four-cell stage and VMZ explants were analyzed for cardiac specific gene expression. GSK3 $\beta$ did not induce appreciable expression of muscle actin, indicating relatively weak dorsalizing ability in VMZ tissue. Like $d k k-1$ and crescent, however, GSK3 $\beta$ yielded robust induction of each of the cardiacspecific genes, including TnIc and $M H C \alpha$ (Fig. 4). This finding indicates that inhibition of $\beta$-catenin is sufficient to induce cardiogenesis.

\section{Overexpression of Wnt3A or Wnt8 blocks cardiogenesis} in DMZ explants

The preceding experiments demonstrated that inhibition of Wnt signaling is sufficient to promote cardiogenesis in noncardiogenic ventral tissue. If the normal function of Wnt antagonism in vivo is to induce cardiogenic meso-

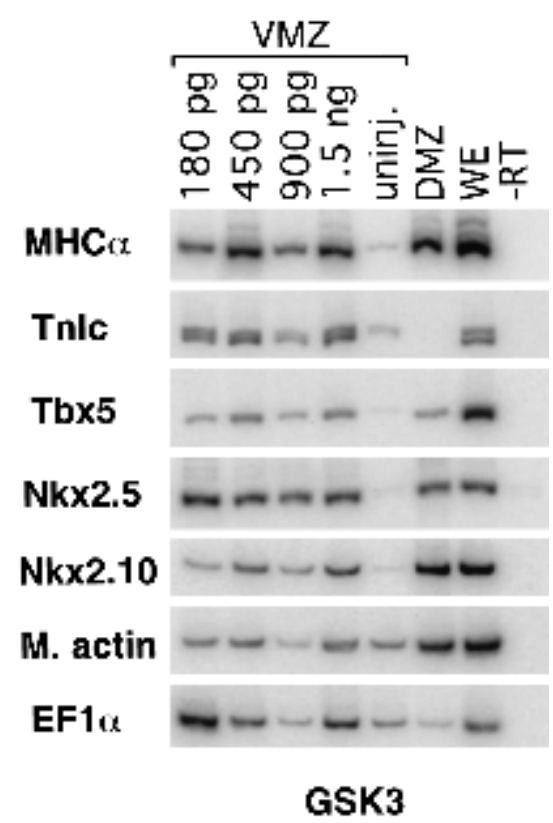

Figure 4. Injection of mRNA encoding GSK3 $\beta$ is sufficient to induce both markers of cardiac mesoderm and heart musclespecific proteins, indicating that inhibition of $\beta$-catenin signal transduction is sufficient to induce cardiogenesis in the VMZ assay. 
derm, then overexpression of Wnt proteins should block cardiogenesis in dorsal mesoderm. Four Wnt genes are known to be expressed during gastrulation: Wnt3A, $W n t 5 A, W n t 8$, and Wnt11. Expression of Wnt8 is normally excluded from the organizer region, whereas $W n t$ $3 A$ and $W n t 11$ are expressed dorsally and $W n t 5 A$ is found diffusely throughout the ectoderm /Christian and Moon 1993; Ku and Melton 1993; Moon et al. 1993; Du et al. 1995; McGrew et al. 1997). We injected Wnt cDNAs into the two dorsal blastomeres of a four-cell embryo and dissected DMZ explants encompassing the organizer and heart primordia at stage 10 (Fig. 5A). Plasmid injections were performed to avoid perturbation of Nieuwkoop center activity that can occur on expression of certain Wnts before the midblastula transition (Smith and Harland 1991; Sokol et al. 1991). Explants were cul- tured to either stage 23 or stage 30 , at which time they were examined for the expression of $N k x 2.5$ or TnIc. Explants were analyzed individually by in situ hybridization, rather than as pools by RT-PCR, as a decrease in the heart-marker expression of a single explant would likely escape detection if it were pooled with other samples exhibiting normal levels of expression.

Figure 5B shows that only Wnt 8 and $W n t 3 A$ were potent inhibitors of endogenous cardiac gene expression. The incidence of explants expressing $N k x 2.5$ decreased to $45.6 \%(n=62)$ and $19.9 \%(n=50)$ on overexpression of Wnt3A and Wnt8, respectively, compared with $98.3 \%$ $(n=65)$ seen in uninjected controls. Injection of these same Wnts also caused the incidence of TnIc expression decline substantially, to $24.2 \%(n=62)$ and $41.1 \%$ $(n=254)$, respectively, from $94.5 \%(n=147)$ in controls.
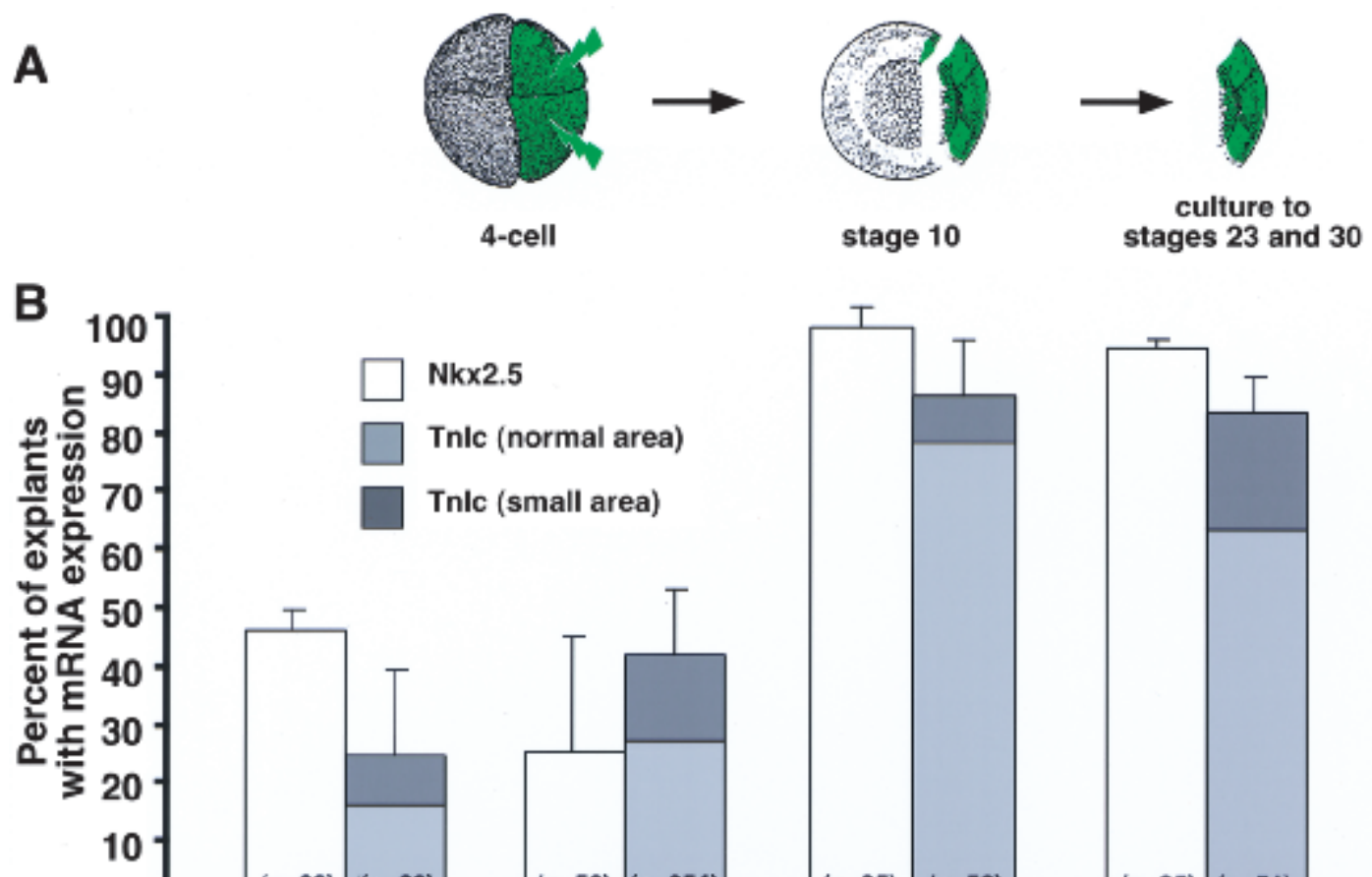
(Fig. 5B). Interestingly, TnIc expression was either absent

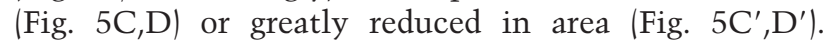
Whereas dorsal overexpression of Wnt8 or Wnt3A prevented specification of the heart field, overexpression of Wnt5A and Wnt11 did not appreciably affect the incidence of either $N k x 2.5(97.5 \%, n=35$ and $94.1 \%, n=35$, respectively) or TnIc expression $(85.9 \%, n=58$ and $83.1 \%, n=51$, respectively; Fig. 5B). Moreover, the expression domains of both heart markers appeared normal (Fig. 5, cf. E,F to control explant in G). Taken together, our data indicate a model in which at least Wnt3A and Wnt 8 activity must be inhibited to specify the heart field in dorsal mesoderm adjacent to the Spemann organizer.

\section{Discussion}

The principal conclusion from our experiments is that Wnt signaling through $\beta$-catenin prevents heart induction and that this inhibition is overcome on the dorsal side of the embryo via the action of specific Wnt antagonists produced by the Spemann organizer. Ectopic expression of either $d k k-1$ or crescent induced both early and late cardiac genetic markers in explants of noncardiogenic VMZ tissue. Remarkably, injection of a single factor induced explants to form rhythmically beating myocardial tubes that morphologically resembled normal hearts. Given the differential ligand specificity of the various Wnt antagonists, the inability of other such proteins to induce heart-specific gene expression indicated that inhibition of particular Wnts is responsible. Accordingly, overexpression of Wnt3A and Wnt8, but not other Wnts thought to be present in the gastrulastage embryo, inhibited endogenous cardiogenesis. These results are the first demonstration of factors that initiate cardiogenesis in Xenopus. We discuss the possible mechanisms by which diffusion of at least Dkk-1 and Crescent from the Spemann organizer induces heart formation in adjacent tissue.

\section{Specific Wnt signaling negatively regulates cardiogenesis}

We speculate that the differential ability to bind and antagonize signaling by various Wnt proteins underlies the specificity seen in the VMZ assay, which revealed that Dkk-1 and Crescent, but not other Wnt inhibitors, are capable of inducing cardiogenesis (Figs. 1,3). Notably, Frzb and dnXwnt8 were unable to induce early or late heart-specific markers (Figs. 1,3). Both of these proteins are effective inhibitors of Wnt8 and/or Wnt3A (Fig. 1; Hoppler et al. 1996; Wang et al. 1997b), which are the only two Wnt proteins among those known to be expressed in the early gastrula-stage embryo that inhibited native cardiogenesis (Fig. 5). Thus, it seems probable that VMZ tissue contains an additional Wnt protein that can be selectively inhibited by Dkk-1 and Crescent but not by the other antagonists tested. Marvin et al. (2001) also show that Crescent and Dkk-1 induce cardiogenesis in chick posterior lateral plate mesoderm.
It is also possible that the heart-inducing activities of Dkk-1 and Crescent derive not from their antagonism of a particular Wnt but instead from an unrecognized ability of these proteins to modulate an alternate molecular pathway, either independently or while bound to Wnt family members. We find this unlikely for two reasons. First, the observation that two structurally unrelated proteins can promote cardiogenesis would indicate that it is their common ability to inhibit Wnt signaling that underlies this phenomenon. Second, our finding that ectopic expression of GSK3 $\beta$, a downstream component of $\beta$-catenin-mediated Wnt signaling, is able to promote cardiogenesis implies that it is this particular pathway that must be inhibited for heart development to occur in vivo. Thus, we favor a model in which Wnt signaling through $\beta$-catenin must be antagonized for heart induction to occur.

Because the VMZ may express particular Wnt proteins not found in the dorsal heart-forming mesoderm, it is not possible to dismiss a cardiogenic role for an antagonist that fails to induce ectopic hearts in the VMZ assay. Frzb, therefore, might contribute to cardiogenesis by reducing Wnt signaling in prospective cardiac mesoderm even if it cannot function in the VMZ assay. Wnt8 and $W n t 3 A$ transcripts are expressed, however, in the heartforming region (Christian and Moon 1993; McGrew et al. 1997) and, as shown here, can inhibit cardiogenesis; therefore, we predict that the combined action of local antagonists, at the very least, must inhibit signaling from these proteins.

\section{Do Wnt antagonists complement or induce an endodermal signal?}

We have shown previously that heart induction in Xenopus requires signals from both the dorsoanterior endoderm that lies beneath the heart primordia and the Spemann organizer and that these tissues together (but not singly) can induce hearts in VMZ explants (Nascone and Mercola 1995). Endoderm competent to induce hearts underlies both the organizer and adjacent heart-forming mesoderm (spanning at least $45^{\circ}$ to either side of the dorsal midline; Schneider and Mercola 1999). $d k k-1$ and crescent (and frzb) are expressed within the deep tissues of the organizer, but not as broadly as the heart-inducing potency of dorsoanterior endoderm (Leyns et al. 1997; Wang et al. 1997a; Glinka et al. 1998; Pera and De Robertis 2000). These data in combination with the results in this article indicate that Wnt antagonism is the organizer-derived signal.

If Dkk-1 and Crescent comprise components of the organizer signal, why can they induce cardiogenesis when organizer tissue alone grafted to VMZ explants are insufficient (Nascone and Mercola 1995)? Two nonmutually exclusive models might explain the unexpected potency of Dkk-1 and Crescent. The simplest explanation is that overexpression of these proteins obviates the usual requirement for an endodermal signal. In this model, the inability of the organizer to induce heart formation on grafting to VMZ explants reflects insufficient levels of Wnt antagonists to induce hearts in the absence 
of a synergistic or additive endodermal factor. This model also predicts that Wnt antagonists from the organizer initiate cardiogenesis normally by acting directly on adjacent mesoderm (as in Fig. 6A). However, overexpression of Dkk-1 and Crescent might dorsoanteriorize residual ventroposterior endoderm contained in the VMZ explants. This idea is consistent with previous studies showing that organizer factors can influence gene expression in underlying dorsoanterior endoderm (Sasai et al. 1996) and is also supported by the induction of $N k \times 2.10$ at stage 30, when it is a specific marker of pharyngeal endoderm that underlies the heart. This model predicts that Wnt antagonists in the organizer initiate cardiogenesis by stimulating the underlying endoderm to induce a second factor that, in turn, acts on the mesoderm (Fig. 6B). It will be interesting to determine whether or not heart induction by Wnt antagonists requires an endodermally derived factor. The extreme fragility of the yolky endoderm cells and the lack of visible landmarks to distinguish them from ventral mesoderm hindered our attempts to remove them from our VMZ explants. Additional experiments are needed to identify the endodermal factor and determine its relationship to Wnt antagonism during heart induction.

\section{Wnt antagonism and heart field specification}

Previous studies have focused on the roles that Wnt and BMP antagonists play in specification of dorsoventral patterning of mesoderm, ectoderm, and in particular, the neuraxis. Consistent with this, ectopic expression of Wnt3A and Wnt8 in DMZ explants resulted in anterior patterning defects in addition to reduced expression of heart-specific mRNAs (Fig. 5C,D). Importantly, the experiments discussed in this article now indicate an additional, previously unrecognized, role for organizer-derived Wnt antagonists in initiating cardiogenesis. We propose that Wnt antagonists expressed in the Spemann organizer induce cardiogenic mesoderm by reducing levels of at least Wnt3A and Wnt8 signaling in adjacent tissue (Fig. 6C). A reduction in Wnt signaling is envisaged to delimit the borders of the cardiogenic mesoderm.

Timed removal of the organizer and endoderm from DMZ explants at stages 10 and 10.5 indicated that organizer-derived signaling is largely completed by stage 10 , whereas the endoderm continues to exert an influence after stage 10.5 (Nascone and Mercola 1995). This observation, combined with the results in this article, indicates that Wnt antagonism acts before the endodermal
Figure 6. Models for induction of cardiogenesis by Wnt antagonism. $(A, B)$ Vegetal view of stage 10 embryo. (Blue) Spemann organizer; (red) heart primordia; (green) deep endoderm. (A) Organizer-derived Wnt antagonists act directly on adjacent mesoderm to create a zone of reduced Wnt signaling. During normal heart induction, the organizer-derived signal is complemented by an endodermal signal (Nascone and Mercola 1995; Schneider and Mercola 1999). (B) Instead of, or in addition to, acting on the mesoderm, organizer-derived Wnt antagonists might induce or activate an endodermal signal. $(C)$ An important consequence of a zone of reduced Wnt signaling in the mesoderm and/or endoderm created by diffusion of the organizer-derived antagonists would be to establish the borders of the heart field. $(D)$ Position of Wnt antagonism in the genetic hierarchy of heart induction (see text).
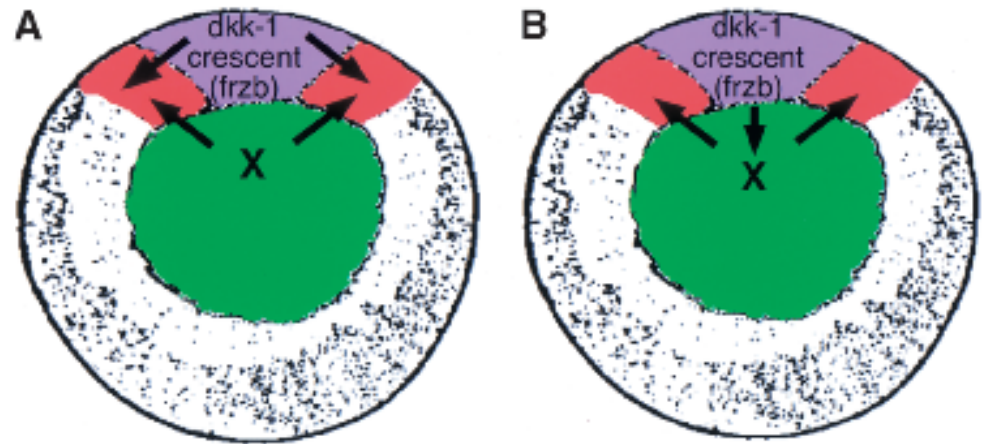

C

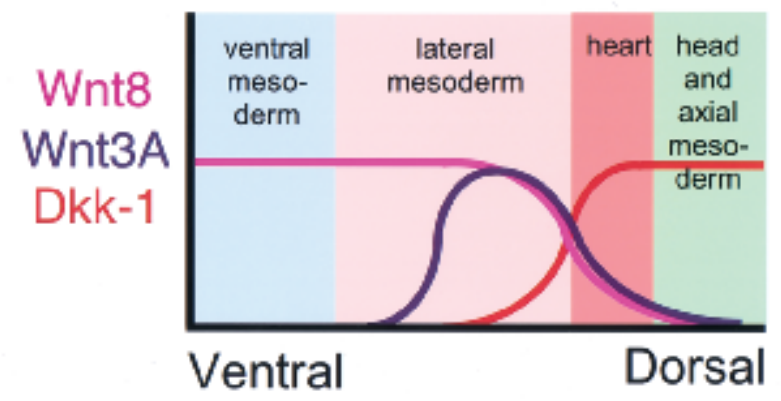

D

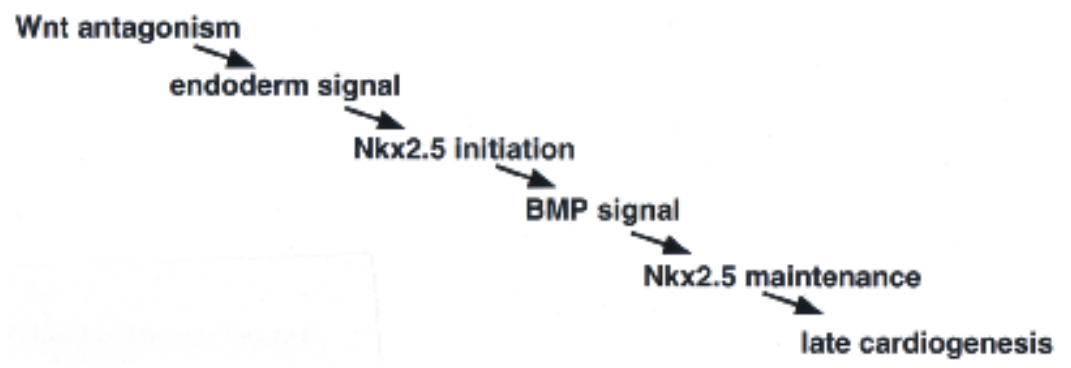


signal and that receipt of both signals leads to $N k x 2.5$ expression (Fig. 6D). Recent evidence from Shi et al. (2000) positions a requirement for BMP further downstream by showing that inhibition of BMP signaling affects maintenance, but not initiation, of Nkx2.5 expression in Xenopus. This overall process is similar to heart induction in avians. On the basis of the finding that BMPs are capable of inducing cardiogenesis in anterior mesoderm medial to the heart-forming region but not in more posterior mesoderm, Schultheiss et al. (1997) proposed that an additional factor must complement the action of BMPs. More recently, Marvin et al. (2001) provided evidence that Crescent, produced by the definitive endoderm, establishes competence in anterior mesodermal cells to form heart in response to BMP. Thus, the same signaling appears to induce Xenopus and chick cardiogenesis, even if different tissues produce the inducing proteins.

\section{Materials and methods}

\section{Embryo and explant culture}

Embryos were fertilized in vitro, dejellied in $2 \%$ cysteine- $\mathrm{HCl}$ (pH 7.8), and maintained in 0.1× MMR. Explant dissections were performed in $0.75 \times$ MMR using an eyelash knife. Embryos were staged according to Nieuwkoop and Faber (1994).

Marginal zone explants were dissected at stage 10. Those explants to be examined by RT-PCR for expression of heart field marker- and heart muscle-specific genes were cultured until sibling embryos were stage 30 . In situ hybridization was performed on explants cultured to the equivalent of stage 23 or stage 30. Explants to be scored for formation of beating hearts were maintained until the equivalent of stage 41 .

\section{Plasmids and mRNA for injections}

mRNA was transcribed from pSP35-chd, pSP64-ngn, pCS2-DKK1, pCS2-Crescent, pCS2-GSK3 $\beta$, pCS2-WIF, pCS2-dnXwnt8, pCS2szl, and pXT7-FrzA using the SP6 and T7 mMessage mMachine kits (Ambion). All cDNAs used encode Xenopus proteins except those for Wnt11 and crescent, which encode chick isoforms. The Xenopus form of crescent was identified while this manuscript was in preparation (Pfeffer et al. 1997; Pera and De Robertis 2000; Shibata et al. 2000) and functions identically to the chick isoform in our assays. Xenopus and chick Crescent share $88 \%$ amino acid positional identity within the cysteine-rich domain. Injections were performed in 3\% Ficoll in $1 \times$ MMR. Embryos were injected equatorially into the two ventral or two dorsal blastomeres at the four-cell stage to target expression to the ventral or dorsal marginal zone. The amount of mRNA injected is given in the text. For plasmid cDNA injections, $75 \mathrm{pg}$ of pCS2-Xwnt3A, pCS2-Xwnt5A, and pCSKA-Xwnt8 and $100 \mathrm{pg}$ of pCS2-cWnt11 supercoiled plasmid constructs were injected.

\section{$R T-P C R$}

RT-PCR was performed as described in Schneider and Mercola (1999). Twenty-five cycles were performed at an annealing temperature of $55^{\circ} \mathrm{C}$, unless otherwise noted. Expression of $E F 1 \alpha$ was used as a positive control for the reverse transcriptase reaction. The following additional primers were used: XNkx2.5+, GAGCTACAGTTGGGTGTGTGTGGT; XNkx2.5-, GTGAA GCGACTAGGTATGTGTTCA; M. actin+, GCTGACAGAA
TGCAGAAG; M. actin-, TTGCTTGGAGGAGTGTGT 122 cycles); TnIc+, CTGATGAGGAAGAGGTAACC; TnIc-, CCT CACGTTCCATTTCTGCC; MHC $\alpha+$, GCCAACGCGAACCTC TCCAAGTTCCG; $M H C \alpha-$, GGTCACATTTTATTTCATGCT GGTTAACAGG; Tbx5+, GGCGGACACAGAGGAGGCTTAT; Tbx5-, GTGGCTGGTGAATCTGGGTGAAC (27 cycles); XNkx2.10+, GCCCCGCTACCTCTACCCCCTTCT; and XNkx2.10-, CСССТCTCACTGTGCCCCCAAAAT $\left(59^{\circ} \mathrm{C}, 28\right.$ cycles).

\section{In situ hybridization}

In situ hybridization was performed according to the protocol of Harland (1991). Digoxygenin-labeled probes were transcribed from the following linearized plasmids: pGEM-XNkx2.5 (XbaI, T7 polymerase) and pBS-TnIc (NotI, T7).

\section{Immunohistochemistry}

Embryos and explants were fixed in MEMFA and stored in $100 \% \mathrm{MeOH}$ (Harland 1991). Immunohistochemistry was performed essentially as described (Hemmati-Brivanlou and Harland 1989|. CT-3, which recognizes the cardiac isoform of troponin $\mathrm{T}$, was used as the primary antibody (Developmental Studies Hybridoma Bank). Rhodamine-conjugated secondary antibodies were used to visualize primary antibody labeling of proteins. Following incubation with secondary antibody, samples were rinsed in $1 \times$ PBS, postfixed in MEMFA, dehydrated through an ethanol series, and embedded in paraffin (Oxford Laboratories).

Embedded explants were sectioned, deparaffinized with xylenes, rehydrated, and stained with DAPI before visualization by epifluorescence microscopy on a Zeiss Axiophot microscope.

\section{Acknowledgments}

We thank Jeremy Green, Richard Maas, Sergei Sokol, and members of the Mercola laboratory for helpful comments and critical reading of the manuscript. We also thank Chris Simpson for histology and Kim Bettano for technical assistance. We are grateful to Martha Marvin and Andrew Lassar for helpful discussions and sharing of results before publication. The pCSKAXwnt 8 and pCS2-GSK3 $\beta$ plasmids were obtained from Randall Moon. These studies were funded by a grant from the NIH (RO1 HL59502 to M.M.).

The publication costs of this article were defrayed in part by payment of page charges. This article must therefore be hereby marked "advertisement" in accordance with 18 USC section 1734 solely to indicate this fact.

\section{References}

Aberle, H., Bauer, A., Stappert, J., Kispert, A., and Kemler, R. 1997. $\beta$-catenin is a target for the ubiquitin-proteasome pathway. EMBO I. 13: 3797-3804.

Andree, B., Duprez, R., Vorbusch, B., Arnold, H.H., and Brand, T. 1998. BMP-2 induces ectopic expression of cardiac lineage markers and interferes with somite formation in chicken embryos. Mech. Dev. 70: 119-131.

Antin, P.B., Taylor, R.G., and Yatskievych, T. 1994. Precardiac mesoderm is specified during gastrulation in quail. Dev. Dyn. 200: 144-154.

Belo, J.A., Bouwmeester, T., Leyns, L., Kertesz, N., Gallo, M., Follettie, M., and De Robertis, E.M. 1997. Cerberus-like is a 
secreted factor with neuralizing activity expressed in the anterior primitive endoderm of the mouse gastrula. Mech. Dev. 68: 45-57.

Belo, J.A., Bachiller, D., Agius, E., Kemp, C., Borges, A.C., Marques, S., Piccolo, S., and De Robertis, E.M. 2000. Cerberus-like is a secreted BMP and nodal antagonist not essential for mouse development. Genesis 26: 265270.

Biben, C., Stanley, E., Fabri, L., Kotecha, S., Rhinn, M., Drinkwater, C., Lah, M., Wang, C.-C., Nash, A., Hilton, D., et al. 1998. Murine cerberus homologue mCer-1: A candidate anterior patterning molecule. Dev. Biol. 194: 135-151.

Bouwmeester, T., Kim, S., Sasai, Y., Lu, B., and De Robertis, E.M. 1996. Cerberus is a head-inducing secreted factor expressed in the anterior endoderm of Spemann's organizer. Nature 382: 595-601.

Christian, J.L. and Moon, R.T. 1993. Interactions between Xwnt-8 and Spemann organizer signaling pathways generate dorsoventral pattern in the embryonic mesoderm of Xenopus. Genes \& Dev. 7: 13-28.

Clement, J.H., Fettes, P., Knochel, S., Lef, J., and Knochel, W. 1995. Bone morphogenetic protein 2 in the early development of Xenopus laevis. Mech. Dev. 52: 357-370.

Dennis, S., Aikawa, M., Szeto, W., d'Amore, P.A., and Papkoff, J. 1999. A secreted Frizzled related protein, FrzA, selectively associates with Wnt-1 protein and regulates Wnt-1 signaling. J. Cell Sci. 112: 3815-3820.

Drysdale, T.A., Tonissen, K.F., Patterson, K.D., Crawford, M.J., and Krieg, P.A. 1994. Cardiac troponin I is a heart-specific marker in the Xenopus embryo: Expression during abnormal heart morphogenesis. Dev. Biol. 154: 432-441.

Du, S.J., Purcell, S.M., Christian, J.L., McGrew, L.L., and Moon, R.T. 1995. Identification of distinct classes and functional domains of Wnts through expression of wild-type and chimeric proteins in Xenopus embryos. Mol. Cell. Biol. 15: $2625-2634$.

Eisenberg, C.A. and Eisenberg, L.M. 1999. WNT11 promotes cardiac tissue formation of early mesoderm. Dev. Dyn. 216: $45-58$.

Esteban, C.R., Capdevila, J., Economides, A.N., Pascual, J., Ortiz, A., and Izpisua-Belmonte, J.C. 1999. The novel Cer-like protein Caronte mediates the establishment of embryonic left-right asymmetry. Nature 410: 243-251.

Eyal-Giladi, H. and Kochav, S. 1976. From cleavage to primitive streak formation: A complementary normal table and a new look at the first stages of the development of the chick. I. General morphology. Dev. Biol. 49: 321-337.

Glinka, A., Wu, W., Onichtchouk, D., Blumenstock, C., and Niehrs, C. 1997. Head induction by simultaneous repression of Bmp and Wnt signalling in Xenopus. Nature 389: $517-$ 519.

Glinka, A., Wu, W., Delius, H., Monaghan, A.P., Blumenstock, C., and Niehrs, C. 1998. Dickkopf-1 is a member of a new family of secreted proteins and functions in head induction. Nature 392: 357-362.

Harland, R.M. 1991. In situ hybridization: An improved whole mount method for Xenopus embryos. Methods Cell Biol. 36: 685-695.

Harland, R. and Gerhart, J. 1997. Formation and function of Spemann's organizer. Annu. Rev. Cell Dev. Biol. 13: 611667.

Hemmati-Brivanlou, A. and Harland, R.M. 1989. Expression of an engrailed-related protein is induced in the anterior neural ectoderm of early Xenopus embryos. Development 106: 611617.

Henry, G.L., Brivanlou, I.H., Kessler, D.S., Hemmati-Brivanlou,
A., and Melton, D.A. 1996. TGF- $\beta$ signals and a prepattern in Xenopus laevis endodermal development. Development 122: 1007-1015.

Hoppler, S., Brown, J.D., and Moon, R.T. 1996. Expression of a dominant-negative Wnt blocks induction of MyoD in Xenopus embryos. Genes \& Dev. 10: 2805-2817.

Horb, M.E. and Thomsen, G.H. 1999. Tbx5 is essential for heart development. Development 126: 1739-1751.

Hsieh, J.-C., Kodjabachian, L., Rebbert, M.L., Rattner, A., Smallwood, P.M., Samos, C.H., Nusse, R., Dawid, I.B., and Nathans, J. 1999. A new secreted protein that binds to Wnt proteins and inhibits their activities. Nature 398: 431-436.

Hsu, D.R., Economides, A.N., Wang, X., Eimon, P.M., and Harland, R.M. 1998. The Xenopus dorsalizing factor Gremlin identifies a novel family of secreted proteins that antagonize BMP activities. Mol. Cell 1: 673-683.

Isaacs, H.V., Tannahill, D., and Slack, J.M.W. 1992. Expression of a novel FGF in the Xenopus embryo: A new candidate inducing factor for mesoderm formation and anteroposterior specification. Development 114: 711-720.

Isaacs, H.V., Pownall, M.E., and Slack, J.M.W. 1995. eFGF is expressed in the dorsal midline of Xenopus laevis. Int. J. Dev. Biol. 39: 575-579.

Jones, C.M., Kuehn, M.R., Hogan, B.L.M., Smith, J.C., and Wright, C.V.E. 1995. Nodal-related signals induce axial mesoderm and dorsalize mesoderm during gastrulation. Development 121: 3651-3662.

Jones, C.M., Dale, L., Hogan, B.L.M., Wright, C.V.E., and Smith, J.C. 1996. Bone morphogenetic protein-4 (BMP-4) acts during gastrula stages to cause ventralization of Xenopus embryos. Development 122: 1545-1554.

Krupnik, V.E., Sharp, J.D., Jiang, C., Robison, K., Chickering, T.W., Amaravadi, L., Brown, D.E., Guyot, D., Mays, G., Leiby, K., et al. 1999. Functional and structural diversity of the human Dickkopf gene family. Gene 238: 303-313.

$\mathrm{Ku}, \mathrm{M}$. and Melton, D.A. 1993. Xwnt-11: A maternally expressed Xenopus wnt gene. Development 119:11611173.

Kuhl, M., Sheldahl, L.C., Malbon, C.C., and Moon, R.T. 2000. $\mathrm{Ca}^{2+} /$ Calmodulin-dependent protein kinase II is stimulated by Wnt and Frizzled homologs and promotes ventral cell fates in Xenopus. J. Biol. Chem. 275: 12701-12711.

Ladd, A.N., Yatskievych, T.A., and Antin, P.B. 1998. Regulation of avian cardiac myogenesis by activin/TGF $\beta$ and bone morphogenetic proteins. Dev. Biol. 204: 407-419.

Lamb, T.M., Knecht, A.K., Smith, W.C., Stachel, S.E., Economides, A.N., Stahl, N., Yancopolous, G.D., and Harland, R.M. 1993. Neural induction by the secreted polypeptide noggin. Science 262: 713-718.

Leyns, L., Bouwmeester, T., Kim, S.-H., Piccolo, S., and De Robertis, E.M. 1997. Frzb-1 is a secreted antagonist of Wnt signaling expressed in the Spemann organizer. Cell 88: 747756.

Logan, M. and Mohun, T. 1993. Induction of cardiac muscle differentiation in isolated animal pole explants of Xenopus laevis embryos. Development 118: 865-875.

Marvin, M.J., Di Rocco, G., Gardiner, A., Bush, S.M., and Lassar, A.B. 2001. Inhibition of Wnt activity induces heart formation from posterior mesoderm. Genes \& Dev. 15: 316-327.

McGrew, L.L., Hoppler, S., and Moon, R.T. 1997. Wnt and FGF pathways cooperatively pattern anteroposterior neural ectoderm in Xenopus. Mech. Dev. 69: 105-114.

Moon, R.T., Campbell, R.M., Christian, J.L., McGrew, L., Shih, J., and Fraser, S. 1993. Xwnt-5A: A maternal Wnt that affects morphogenetic movements after overexpression in embryos of Xenopus laevis. Development 119: 97-111. 
Moon, R.T., Brown, J.D., and Torres, M. 1997. WNTs modulate cell fate and behavior during vertebrate development. TIGS 13: 157-162.

Nascone, N. and Mercola, M. 1995. An inductive role for endoderm in Xenopus cardiogenesis. Development 121: 515-523.

Newman, C.S. and Krieg, P.A. 1998. tinman-related genes expressed during heart development in Xenopus. Dev. Gen. 22: 230-238.

Newman, C.S., Reecy, J., Grow, M.W., Ni, K., Boettger, T., Kessel, M., Schwartz, R.J., and Krieg, P.A. 2000. Transient cardiac expression of the tinman-family homeobox gene XNkx2-10. Mech. Dev. 91: 369-373.

Nieuwkoop, P.D. and Faber, J. 1994. Normal table of Xenopus laevis (Daudin): A systematical and chronological survey of the development from the fertilized egg till the end of metamorphosis. Garland, New York.

Pearce, J.J.H., Penny, G., and Rossant, J. 1999. A mouse cerberus/DAN-related gene family. Dev. Biol. 209: 98-110.

Pera, E.M. and De Robertis, E.M. 2000. A direct screen for secreted proteins in Xenopus embryos identifies distinct activities for the Wnt antagonists Crescent and Frzb-1. Mech. Dev. 96: 183-195.

Pfeffer, P.L., De Robertis, E.M., and Izpisua-Belmonte, J.-C. 1997. Crescent, a novel chick gene encoding a Frizzled-like cysteine-rich domain, is expressed in anterior regions during early embryogenesis. J. Dev. Biol. 41: 449-458.

Piccolo, S., Agius, E., Leyns, L., Bhattacharyya, S., Grunz, H., Bouwmeester, T., and De Robertis, E.M. 1999. The head inducer Cerberus is a multifunctional antagonist of Nodal, BMP and Wnt signals. Nature 397: 707-710.

Salic, A.N., Kroll, K.L., Evans, L.M., and Kirschner, M.W. 1997. Sizzled: A secreted Xwnt8 antagonist expressed in the ventral marginal zone of Xenopus embryos. Development 124: 4739-4748.

Sasai, Y., Lu, B., Steinbesser, H., Geissert, D., Gont, L.K., and De Robertis, E.M. 1994. Xenopus chordin: A novel dorsalizing factor activated by organizer-specific homeobox genes. Cell 79: 779-790.

Sasai, Y., Lu, B., Piccolo, S., and De Robertis, E.M. 1996. Endoderm induction by the organizer-secreted factors chordin and noggin in Xenopus animal caps. EMBO J. 15: 45474555.

Sater, A.K. and Jacobson, A.G. 1989. The specification of heart mesoderm occurs during gastrulation in Xenopus laevis. Development 105: 821-830.

-1990. The role of the dorsal lip in the induction of heart mesoderm in Xenopus laevis. Development 108: 461-470.

Schlange, T., Andree, B., Arnold, H.H., and Brand, T. 2000. BMP2 is required for early heart development during a distinct time period. Mech. Dev. 91: 259-270.

Schneider, V.A. and Mercola, M. 1999. Spatially distinct head and heart inducers within the Xenopus organizer region. Curr. Biol. 9: 800-809.

Schultheiss, T.M., Xydas, S., and Lassar, A.B. 1995. Induction of avian cardiac myogenesis by anterior endoderm. Development 121: 4203-4214.

Schultheiss, T.M., Burch, J.B.E., and Lassar, A.B. 1997. A role for bone morphogenetic proteins in the induction of cardiac myogenesis. Genes \& Dev. 11: 451-462.

Shawlot, W., Deng, J.M., and Behringer, R.R. 1998. Expression of the mouse cerberus-related gene, Cerrl, suggests a role in anterior neural induction and somitogenesis. Proc. Natl. Acad. Sci. 95: 6198-6203.

Sheldahl, L.C., Park, M., Malbon, C.C., and Moon, R.T. 1999. Protein kinase $\mathrm{C}$ is differentially stimulated by Wnt and Frizzled homologs in a G-protein-dependent manner. Curr.
Biol. 9: 695-698.

Shi, Y., Katsev, S., Cai, C., and Evans, S. 2000. BMP is required for heart formation in vertebrates. Dev. Biol. 224: 226-237.

Shibata, M., Ono, H., Hikasa, H., Shinga, J., and Taira, M. 2000. Xenopus crescent encoding a Frizzled-like domain is expressed in the Spemann organizer and pronephros. Mech. Dev. 96: 243-246.

Simpson, E.H., Johnson, D.K., Hunsicker, P., Suffolk, R., Jordan, S.A., and Jackson, I.J. 1999. The mouse Cer1 (Cerberus related or homologue) gene is not required for anterior pattern formation. Dev. Biol. 213: 202-206.

Smith, W.C. and Harland, R.M. 1991. Injected Xwnt-8 RNA acts early in Xenopus embryos to promote formation of a vegetal dorsalizing center. Cell 67: 753-765.

Sokol, S., Christian, J.L., Moon, R.T., and Melton, D.A. 1991. Injected Wnt RNA induces a complete body axis in Xenopus embryos. Cell 67: 741-752.

Song, J. and Slack, J.M.W. 1994. Spatial and temporal expression of basic fibroblast growth factor (FGF-2) mRNA and protein in early Xenopus development. Mech. Dev. 48: 141-151.

Sugi, Y. and Lough, J. 1994. Anterior endoderm is a specific effector of terminal cardiac myocyte differentiation of cells from the embryonic heart forming region. Dev. Dyn. 200: $155-162$.

Suzuki, A., Nishimatsu, S., Murakami, K., and Ueno, N. 1993. Differential expression of Xenopus BMPs in early embryos and tissues. Zool. Sci. 10: 175-178.

Tannahill, D., Isaacs, H.V., Close, M.J., Peters, G., and Slack, J.M.W. 1992. Developmental expression of the Xenopus int-2 (FGF-3) gene: Activation by mesodermal and neural induction. Development 115: 695-702.

Tonissen, K.F., Drysdale, T.A., Lints, T.J., Harvey, R.P., and Krieg, P.A. 1994. XNkx-2.5, a Xenopus gene related to NkX2.5 and tinman: Evidence for a conserved role in cardiac development. Dev. Biol. 162: 325-328.

Wang, S., Krinks, M., Lin, K., Luyten, F.P., and Moos Jr., M. 1997a. Frzb, a secreted protein expressed in the Spemann organizer, binds and inhibits Wnt-8. Cell 88: 757-766.

Wang, S., Krinks, M., and Moos, M. 1997b. Frzb-1, an antagonist of Wnt-1 and Wnt-8, does not block signaling by Wnts -3A, -5A or -11. Biochem. Biophys. Res. Comm. 236: 502-504.

Wu, X., Golden, K., and Bodmer, R. 1995. Heart development in Drosophila requires the segment polarity gene wingless. Dev. Biol. 169: 619-628.

$\mathrm{Xu}$, Q., D'Amore, P.A., and Sokol, S.Y. 1998. Functional and biochemical interactions of Wnts with FrzA, a secreted Wnt antagonist. Development 125: 4767-4776.

Yamagishi, T., Nishimatsu, S., Nomura, S., Asashima, M., Murakami, K., and Ueno, N. 1995. Expression of BMP-2,4 genes during early development in Xenopus. Zool. Sci. 12: 355358.

Yatskievych, T.A., Ladd, A.N., and Antin, P.B. 1997. Induction of cardiac myogenesis in avian pregastrula epiblast: The role of the hypoblast and activin. Development 124: 2561-2570.

Yokouchi, Y., Vogan, K.J., Pearse, R.V., and Tabin, C.J. 1999. Antagonistic signaling by Caronte, a novel Cerberus-related gene, establishes left-right asymmetric gene expression. Cell 98: 573-583.

Zhu, L., Marvin, M.J., Gardiner, A., Lassar, A.B., Mercola, M., Stern, C.D., and Levin, M. 1999. Cerberus regulates left-right asymmetry of the embryonic head and heart. Curr. Biol. 9: 931-938.

Zimmerman, L.B., De Jesus-Escobar, J.M., and Harland, R.M. 1996. The Spemann organizer signal noggin binds and inactivates bone morphogenetic protein 4. Cell 86: 599-606. 


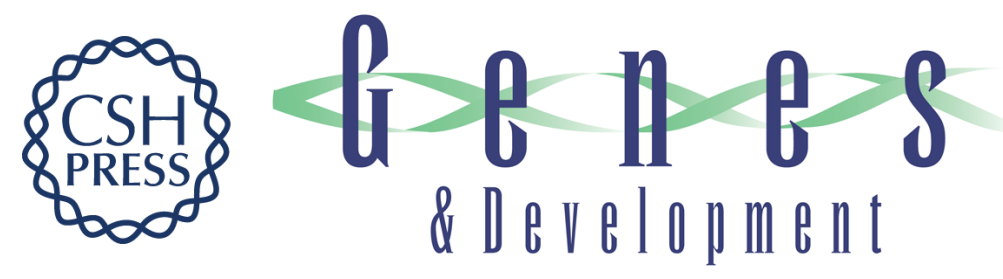

\section{Wnt antagonism initiates cardiogenesis in Xenopus laevis}

Valerie A. Schneider and Mark Mercola

Genes Dev. 2001, 15:

Access the most recent version at doi:10.1101/gad.855601

References This article cites 76 articles, 26 of which can be accessed free at: http://genesdev.cshlp.org/content/15/3/304.full.html\#ref-list-1

License

Email Alerting Receive free email alerts when new articles cite this article - sign up in the box at the top Service right corner of the article or click here.

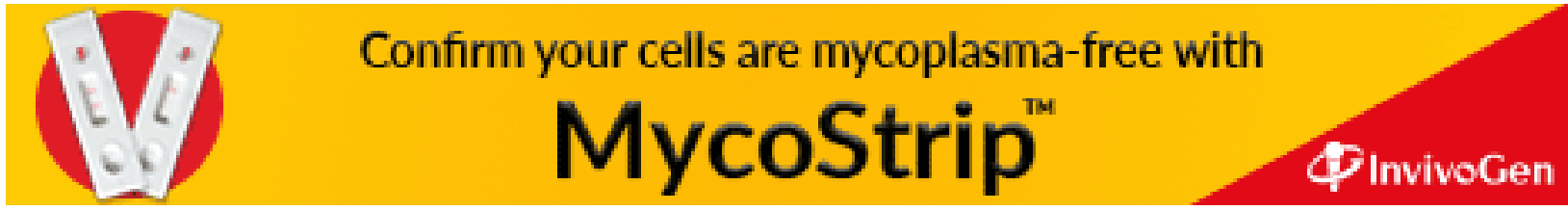

